Mathematical and Computational Applications, Vol. 16, No. 4, pp. 979, 2011.

(C) Association for Scientific Research

\title{
Erratum to: "High-Order Finite Difference Schemes for Solving the Advection-Diffusion Equation, Mathematical and Computational Applications, Vol. 15, No. 3, 449-460, 2010."
}

\author{
Murat Sari ${ }^{1, *}$, Gürhan Gürarslan ${ }^{2}$ and Asuman Zeytinoğlu ${ }^{3}$ \\ ${ }^{1}$ Department of Mathematics, Faculty of Art and Science, Pamukkale \\ University, Denizli 20070, Turkey.msari@pau.edu.tr \\ ${ }^{2}$ Department of Civil Engineering, Faculty of Engineering, Pamukkale \\ University, Denizli 20070, Turkey. \\ ${ }^{3}$ Department of Mathematics, Faculty of Art and Science, Süleyman Demirel \\ University, Isparta 32260, Turkey.
}

There are two points mistyped in the paper need to be changed as follows:

In Example 2, in the first sentence the solution interval erroneously given by $3.5 \leq x \leq 6.5$. The corrected form of the interval is: $0 \leq x \leq 9$.

The sentence "Comparisons of the results with exact solutions showed that the present schemes are capable of solving the." in "Conclusion" section should be changed to "Comparisons of the results with exact solutions showed that the present schemes are capable of solving the advection-diffusion equation and are also capable of producing highly accurate solutions" 